\title{
Erratum to: The t-Modified Self-Shrinking Generator
}

Sara D. Cardell and Amparo Fúster-Sabater

\author{
Erratum to: \\ Chapter "The Modified Self-Shrinking Generator?" in: \\ Y. Shi et al. (Eds.): Computational Science - ICCS 2018, \\ LNCS 10860, \\ https://doi.org/10.1007/978-3-319-93698-7_50
}

The original version of this chapter had a typing error in the title. The title has now been corrected from "The Modified Self-Shrinking Generator?" to "The t-Modified Self-Shrinking Generator”.

\footnotetext{
The updated online version of this chapter can be found at https://doi.org/10.1007/978-3-319-93698-7_50 